\title{
Pectoral nerves I block is associated with a significant motor blockade with no dermatomal sensory changes: a prospective volunteer randomized-controlled double-blind study \\ Le bloc I des nerfs pectoraux est associé à un bloc moteur significatif sans modifications de la sensibilité dermatomale : étude prospective contrôlée à double insu chez des volontaires
}

\author{
Jean Desroches, MD, FRCPC • Marc Belliveau, MD, FRCPC • Carole Bilodeau, Pht • \\ Michel Landry, MD, FRCPC • Maxim Roy, MD $\cdot$ Pierre Beaulieu, MD, PhD, FRCA \\ Received: 14 December 2017/Revised: 25 February 2018/Accepted: 25 February 2018/Published online: 29 March 2018 \\ (C) Canadian Anesthesiologists' Society 2018
}

\begin{abstract}
Purpose The pectoral nerves (PECS) I block, first described in 2011 for surgery involving the pectoralis muscle, has principally been used for breast cancer surgery. No formal evaluation of its differential motorand sensory-blocking abilities has been reported. We hypothesize that the PECS I block will produce a motor block of the pectoralis muscles with diminished upper limb adduction strength as measured with a handheld dynamometer.

Methods We conducted a PECS I block in a randomized placebo-controlled trial in six healthy subjects who received $0.4 \mathrm{~mL} \cdot \mathrm{kg}^{-1}$ of $0.9 \%$ saline (placebo) on one side and bupivacaine (0.25\% with 1:400 000 epinephrine) on the other. We measured both upper limb adduction strength with a dynamometer and sensory skin levels over the thorax.

Results The mean (standard deviation [SD]) adductor strength evaluated before the block was 119.4 (20.7) Newtons (N). After the PECS I block with bupivacaine, the
\end{abstract}

J. Desroches, MD, FRCPC · M. Belliveau, MD, FRCPC . M. Landry, MD, FRCPC

Department of Anesthesiology, Hôtel-Dieu de St Jérôme,

St Jérôme, QC, Canada

C. Bilodeau, Pht

Department of Physiotherapy, Hôtel-Dieu de St Jérôme,

St-Jérôme, QC, Canada

M. Roy, MD · P. Beaulieu, MD, PhD, FRCA ( $\square)$

Department of Anesthesiology, Centre Hospitalier de

l'Université de Montréal, 1000 rue St-Denis, Montreal, QC H2X 0C1, Canada

e-mail: maxim.roy20@gmail.com mean (SD) strength of 54.2 (16.3) $N$ was compared with 116.0 (30.4) $N$ in the placebo group (difference in means $61.8 \mathrm{~N} ; 95 \%$ confidence interval [CI], 27.8 to $95.8 \mathrm{~N}$; $P=0.005)$, showing a $54.6 \%$ (95\% CI, 43.6 to $65.6 \%)$ reduction in adductor strength. There was no difference in dermatomal skin sensory testing between the placebo and bupivacaine sides.

Conclusions This study shows that a PECS I block produces motor blockade as shown by reduced upper limb adductor strength without any overlying dermatomal sensory loss.

Trial registration $w w w . c l i n i c a l t r i a l s . g o v ~(N C T 03040167)$ 2 February 2017.

\section{Résumé}

Objectif Le bloc I des nerfs pectoraux (PECS), décrit pour la première fois en 2011 pour la chirurgie impliquant le muscle grand pectoral, a été principalement utilisé pour la chirurgie carcinologique du sein. Aucune évaluation formelle de ses capacités de blocage différentiel moteur ou sensitifn'a été publiée. Nous avons émis l'hypothèse que le bloc PECS I induit un bloc moteur des muscles pectoraux avec une diminution de la force d'adduction du membre supérieur, mesurée par un dynamomètre portatif.

Méthodes Nous avons réalisé des blocs PECS I au cours d'un essai randomisé contrôlé par placebo chez six sujets en bonne santé qui ont reçu $0,4 \mathrm{~mL} \cdot \mathrm{kg}^{-1}$ de solution saline à $0,9 \%$ (placebo) d'un côté et de la bupivacaïne $(0,25 \%$ avec de l'épinéphrine au 1/400 000) de l'autre côté. Nous avons mesuré la force d'adduction des deux membres supérieurs avec un dynamomètre et les niveaux de sensibilité cutanée sur le thorax. 
Résultats La force moyenne de l'adducteur (écart-type [ET]) évaluée avant le bloc était de 119,4 (20,7) Newtons (N). Après le bloc PECS I avec la bupivacaïne, la force moyenne (ET) était de $54,2(16,3) N$ comparée à $116,0(30,4) \mathrm{N}$ dans le groupe placebo (différence des moyennes $61,8 \mathrm{~N}$; intervalle de confiance à $95 \%$ [IC] : 27,8 à 95,8; $P=0,005)$, démontrant une baisse de 54,6\% (IC à 95\% : 43,6 à 65,6\%) de la force d'adduction. Il n'y a pas eu de différence pour les tests de sensibilité des dermatomes cutanés entre les côtés ayant reçu le placebo ou la bupivacaïne.

Conclusions Cette étude démontre qu'un bloc PECS I entraîne un bloc moteur mis en évidence par la baisse de la force d'adduction des membres supérieurs sans perte de la sensibilité des dermatomes sus-jacents.

Enregistrement de l'essai clinique www.clinicaltrials. gov (NCT03040167) 2 février 2017.

The pectoral nerves (PECS) block was first described by Blanco in $2011^{1}$ in a letter to the editor and was later named the PECS I block. ${ }^{2}$ In his original letter, Blanco stated that the PECS I could be an alternative to the paravertebral block, thereby implying that the PECS I blocks the intercostal nerves or its cutaneous branches. Anatomically, the PECS I block aims to anesthetize the medial and lateral pectoral nerves, which innervate the pectoralis major and minor muscles. Thus, its primary indication would be for surgeries having pectoralis muscle involvement such as sub-pectoral breast augmentation surgery and modified radical mastectomies. ${ }^{3}$ In fact, there is a paucity of evidence for its clinical benefit. ${ }^{3}$

Soon after the publication of the PECS I block, Blanco proposed a modified form of the block, called PECS II, with a second injection made between the pectoralis minor and the serratus anterior, ${ }^{2}$ which aimed at blocking the lateral branches of the intercostal nerves and the long thoracic nerve. Since then, the majority of literature has studied this modified technique ${ }^{4-7}$ and no randomized placebo-controlled study has been published for the isolated PECS I. Only one recent study compared PECS I and PECS II after modified radical mastectomy, but without placebo control. ${ }^{8}$ The current literature only indirectly shows that the PECS I block may be effective by showing that a solution containing dye injected between the pectoralis major and minor muscles stains the pectoral nerves ${ }^{9}$ but direct demonstration of its blocking of pectoral nerves has not been performed.

The pectoral nerves are generally considered motor nerves but they may also contain sensory fibres, having an analgesic potential when blocked in a context where surgery may produce pectoralis muscle spasm, for example. $^{10}$ The major physiologic function of the pectoral nerves is the innervation of the pectoralis muscles, which are the main contributors to upper limb adduction. Hence, appropriate spread of local anesthetic with a PECS I block to the pectoral nerves should produce diminished adductor strength of the arm. Accordingly, we hypothesized that a PECS I block would diminish adductor strength of the upper limb (primary endpoint) with no overlying sensory change along the thoracic dermatomes.

\section{Methods}

Following ethics committee approval (27 February 2017), registration to clinicaltrials.gov (NCT-03040167), and written informed consent, we proceeded with studying the PECS I block in six adult female volunteers. This volunteer study was the first part of a two-part study wherein the second part recruited patients undergoing breast augmentation surgery. Exclusion criteria included: allergies to bupivacaine, coagulopathy, local infection, pregnancy, breast feeding, chronic pain, muscle relaxant use, any condition that could affect upper limb strength or sensation of the thoracic dermatomes, and prior breast surgery. The study took place in May 2017.

Volunteers had bilateral PECS I blocks and randomly received either local anesthetic or the placebo to one of each of the sides (i.e., each patient served as their own control). The anesthesiologist doing the block, the volunteers, and the physiotherapist doing the sensory and motor evaluations were all blinded to which side received the local anesthetic or the saline solution.

Before the blocks were performed, sensory testing to touch and cold was evaluated on anterior, lateral, and posterior aspects of the hemithorax. Adduction strength of the upper limbs was also measured by a physiotherapist. The strength was measured in a standardized manner using a dynamometer (MedUp, Quebec City, QC, Canada), over three repeated five- to ten-second maximal effort contractions with the patient being allowed one minute of rest between each repetition. The volunteer was in a supine position, knees flexed, with the upper limb tested being flexed at $90^{\circ}$ at the shoulder with a slight internal rotation and the elbow in extension. The movement requested for the volunteer was a horizontal adduction of the upper limb toward the opposite shoulder while keeping the elbow in extension. The physiotherapist was standing on the opposite side of the shoulder being evaluated. The dynamometer was positioned just distal to the elbow on the forearm.

Sensory testing was conducted with ice and a 10-g von Frey monofilament (Fabrication Enterprises, White Plains, NY, USA). The physiotherapist, blinded to the block 
solution used, started with ice sensory testing on the left side of the volunteer followed by the right side and then with the monofilament in the same side order. The forehead was used as an indicator of normal sensation. Then, using a thoracic dermatome map as a reference, the thoracic dermatomes starting from T2-T10 first on the anterior, then on the lateral, and finally on the posterior aspects of the thorax were evaluated. All measurements were binary (i.e., normal or diminished). To avoid issues of left- or righthand dominance of the volunteers, the pre- and post-block strength evaluations were not compared between the limbs.

The bilateral PECS I blocks were performed by the same anesthesiologist (J.D.). Prior to performance of the PECS I block, the volunteers had standard monitors applied, received supplemental oxygenation via face mask, and were sedated with intravenous propofol $(20-30 \mathrm{mg})$ and remifentanil $(30-45 \mu \mathrm{g})$. After sterile preparation and disinfection of the thoracic skin area, an ultrasound image of the pectoral region was produced using a 4-12$\mathrm{MHz}$ linear probe (GE Logic E, Jiangsu, China) placed obliquely under the clavicle, perpendicular to the principal axis of the pectoralis minor muscle (Fig. 1). The medial end of the probe was angulated cephalad nearly touching the clavicle while the lateral end was positioned more caudally. This positioning of the probe provides an ideal transverse view of the pectoral branch of the thoracoacromial artery. An 80-mm echogenic short-bevel needle (Sonotap; Pajunk, Geisingen, Germany) was then introduced in plane in a caudo-lateral to cranio-medial axis. The needle tip was placed between the pectoralis major and minor muscles close to the pectoral branch of the thoraco-acromial artery near the mid-clavicular area. A solution of $0.4 \mathrm{~mL} \cdot \mathrm{kg}^{-1}$ bupivacaine $0.25 \%$ with epinephrine $2.5 \mu \mathrm{g} \cdot \mathrm{mL}^{-1}$ or $0.4 \mathrm{~mL} \cdot \mathrm{kg}^{-1}$ of $0.9 \%$ sodium chloride (placebo) was then randomly injected, one side assigned to the placebo and the other to the local anesthetic solution. The various syringes used in the study were prepared and labelled in an identical manner by a second anesthesiologist (M.L.) not involved in the subsequent evaluation of the volunteers with numbers and sides that had been attributed randomly to each volunteer. The second anesthesiologist was the only person in the study who kept and had access to the random list and did not divulge information at any time to the anesthesiologist performing the block. The randomization was generated using the online tool Random.org.

The block was assessed $40 \mathrm{~min}$ after injection. In addition, the volunteers were asked which side they thought the local anesthetic had been injected into. A further follow-up was conducted by phone $24 \mathrm{hr}$ after block performance to collect complication data. The primary outcome was the difference in strength between upper limb adduction before and after pectoral nerve block completion. Secondary outcomes were skin sensory testing to ice and monofilament as described above.

\section{Statistical analysis}

The number of volunteers was calculated using the sample size formula for a paired t-test. The patient being her own control, to demonstrate a clinically significant difference of a $50 \%$ reduction in adduction strength (120 Newton $[\mathrm{N}]$ to

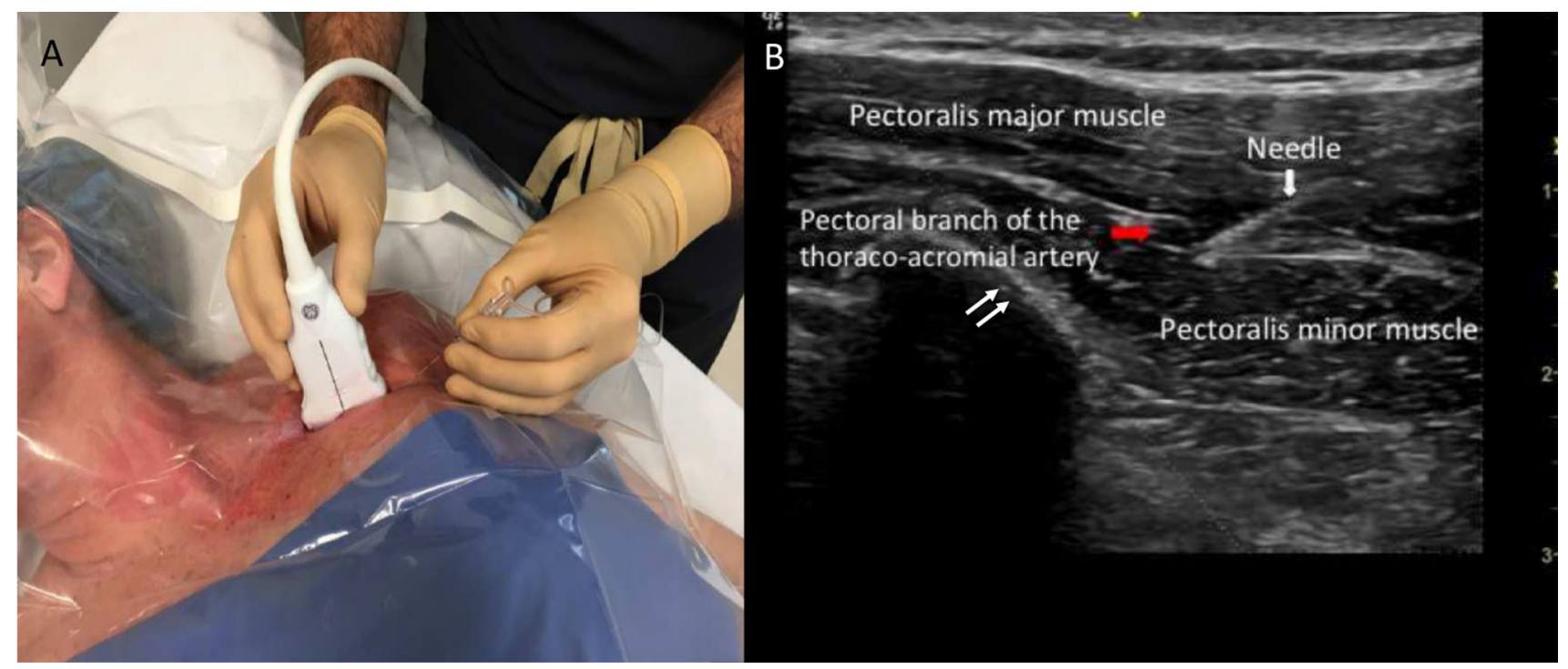

Fig. 1 A) A pectoral nerves I block being performed by placing the ultrasound probe on a volunteer's chest just below the clavicle prior to the injection of bupivacaine or placebo. B) The corresponding ultrasound image with the block needle tip near the thoraco-acromial artery (red) is also shown. The second rib is marked with a double arrow 
$60 \mathrm{~N}$; estimated standard deviation [SD], $30 \mathrm{~N}$ ), with a power of $80 \%$ and an alpha of $5 \%$, six volunteers were enrolled.

After testing the data for normality using the ShapiroWilk and Levene tests for the anesthetic block (before and after) and the equality of variances, respectively, the data are presented as mean (SD). The primary endpoint of adductor strength was compared between groups using a Student $t$ test for matched samples. $P<0.05$ was considered the level for significance. The analysis was performed using SPSS Statistics 20 (NY, USA).

\section{Results}

Volunteers had a mean (SD) age of 30.3 (10.4) yr, weighed 62.3 (4.4) kg, and were $166(5) \mathrm{cm}$ in height. The mean (SD) time to PECS I block evaluation was 39.5 (5.0) minutes. The baseline mean (SD) adductor strength evaluated before the block was 119.4 (20.7) N. After the PECS I block with bupivacaine, the mean (SD) strength was 54.2 (16.3) $\mathrm{N}$ compared with 116.0 (30.4) in the placebo group (difference in means $61.8 \mathrm{~N} ; 95 \%$ confidence interval [CI], 27.8 to $95.8 \mathrm{~N} ; P=0.005$ ), thus showing a $54.6 \%(95 \% \mathrm{CI}, 43.6$ to $65.6 \%)$ reduction in adductor strength. Detailed motor variables are presented in Fig. 2.

When asked into which side the volunteers thought the local anesthetic had been injected, all of them identified it correctly. We observed a slight mean reduction in placebo arm adduction (2.8\% reduction $95 \% \mathrm{CI},-20.9 \%$ to $15.1 \%$; $P=0.69$ ) between the baseline and post-placebo injection times. We did not find any difference between placebo and local anesthetic for the sensory examination with the von
Frey monofilament or ice evaluations. No complications were observed during our study.

\section{Discussion}

This study confirmed that a PECS I block does block the pectoral nerves as shown by the motor block of the pectoralis muscles that was shown translating into diminished upper limb adduction strength. The PECS I block did not produce any sensory change in the corresponding thoracic dermatomes. Therefore, in clinical practice, before surgery, it would not be possible to show a successful PECS I block by any accompanying sensory change; however, an objective reduction in motor strength and possibly by a subjective upper limb adduction weakness might be useful.

The main aim in this study was to objectively show that the PECS I block does produce a block of the pectoral nerves. This step was necessary before conducting clinical trials on the PECS I block, because subsequent clinical studies that would not show clinical benefits of the PECS I block could have argued that the PECS I does not block the pectoral nerves. We consider that in clinical practice it would not be practical to systematically evaluate the diminished strength of shoulder adduction after a PECS I block because of time and equipment constraints. In a way, the PECS 1 block is similar to the obturator nerve block in the difficulty of evaluating simply its efficacy. The obturator nerve block produces no sensory change in $57 \%$ of the patients and the best method to demonstrate its efficacy is also by showing an objective diminished adduction strength of the hip. ${ }^{11}$

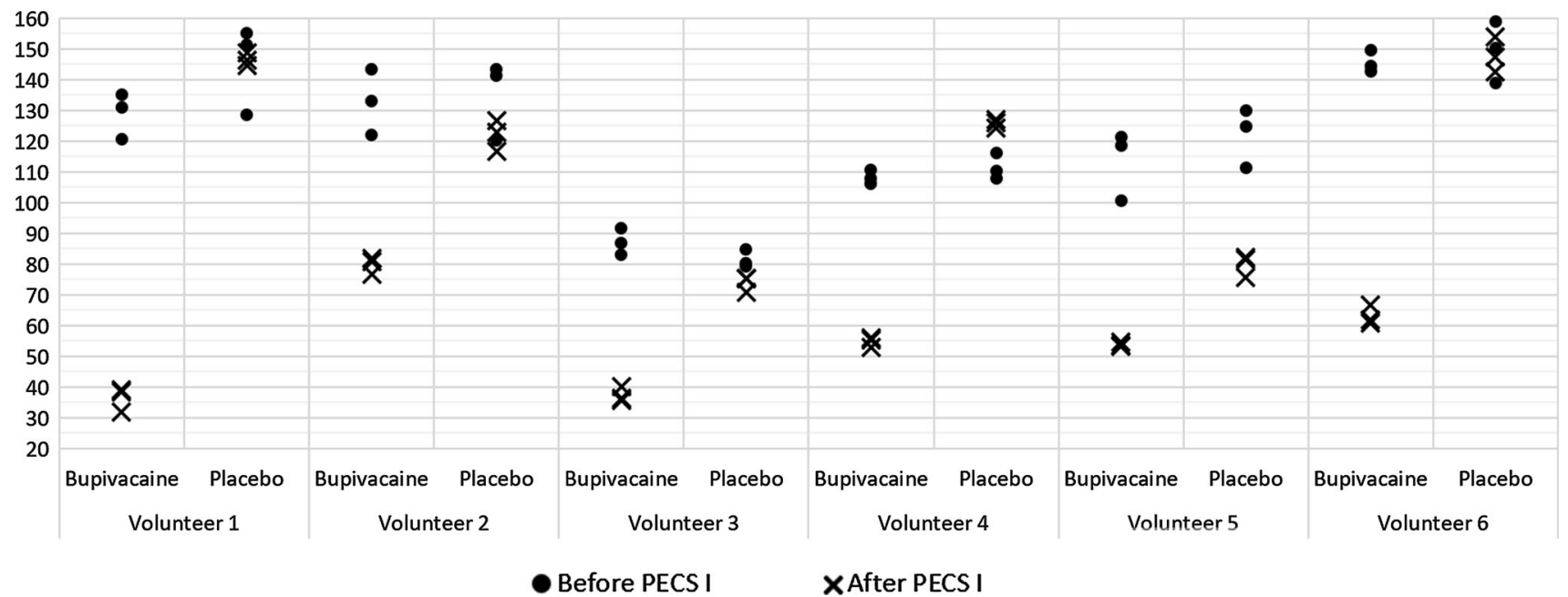

Fig. 2 Observed measures of strength (Newtons [N]) among the volunteers before and after a pectoral nerves (PECS) I injection of either bupivacaine or placebo, with each volunteer serving as their own control 
The pectoralis major muscle is the most powerful adductor muscle of the shoulder ${ }^{12}$ and its strength can easily be measured with a hand-held dynamometer. ${ }^{13}$ The dynamometer has been used to diagnose and evaluate pectoralis major muscle tears ${ }^{14}$ as well as to evaluate muscle recovery after rupture or tear of this muscle. ${ }^{15,16}$ Nevertheless, this method of evaluation is not practical in the clinical anesthesia setting.

Another question that arises is that since pectoral nerves are considered motor nerves, should they be expected to produce analgesia? Although they have been anatomically described as motor nerves, they are likely mixed nerves in similar fashion to the spinal accessory nerve. This nerve is considered a motor nerve but contains many $\mathrm{C}$ nerve fibres. ${ }^{17}$ In fact, we know that the lateral pectoral nerve innervates the articular portion of the shoulder in $67 \%$ of patients ${ }^{18}$ and occasionally gives off cutaneous sensory branches. ${ }^{19}$ The effective analgesia of blocking the pectoral nerves might come from its unappreciated sensory component or also from its motor function where a motor block could produce a reduced muscle spasm of the pectoralis major muscle induced by surgical trauma. ${ }^{10}$

The vast majority of recent papers have evaluated the PECS II approach. ${ }^{4-7}$ Very few studies or case reports have been published for PECS I block alone. ${ }^{20,21}$ One must also take into consideration that most of these studies might not have been using a PECS I block for the appropriate type of surgery as pectoral nerve blockade may not be of major importance in mastectomies where mammary tissue receives the majority of trauma and not the pectoralis muscles themselves. ${ }^{2}$ Still, the favourable use of PECS I in breast cancer surgery has been described in the retrospective study by Abdallah et al $^{22}$ who showed comparable efficacy between the PECS I and the serratus anterior plane block. Nevertheless, the efficacy of PECS I in this type of surgery not involving the pectoralis muscles might come from the axillary diffusion of the local anesthetic towards the lateral branches of the intercostal nerves and not by blocking the pectoral nerves. ${ }^{23}$ The absence of sensory blockade in our study, however, invalidates this hypothesis.

There has been only one double-blind randomized placebo-controlled study of the analgesic efficacy of the PECS II block. ${ }^{4}$ Most PECS II studies were without placebo control $^{5-7}$ and were conducted for breast cancer surgeries that did not involve the pectoralis muscles; therefore, we can question the usefulness of the interpectoral injection of the PECS II block. For breast lumpectomy, and even total mastectomy, Woodworth does not recommend using a PECS II block because the interpectoral injection (which is equivalent to a PECS I block) is unnecessary. ${ }^{3}$ It is also with this reasoning that Hetta and Rezk ${ }^{24}$ studied the efficacy of a modified PECS
II, without the component of the interpectoral injection, on breast surgeries. This study had no control group, however, and compared a pectoral group with the paravertebral block.

We therefore need well-conducted trials to evaluate the clinical efficacy of the PECS I block. It is crucial that these studies concentrate on surgeries where the use of PECS I appears anatomically appropriate, such as sub-pectoral breast augmentation. The benefit of blocking the pectoral nerves during breast augmentation surgery has been shown clinically by injecting local anesthetic in the interpectoral space during surgery ${ }^{25,26}$ and by botulinum toxin injection in pectoralis muscles to control pain after mastectomy and breast expander insertion. ${ }^{27}$

The volume of local anesthetic $\left(0.4 \mathrm{~mL} \cdot \mathrm{kg}^{-1}\right)$ used in our study is the same as in Blanco's original 2011 letter. $^{1}$ This volume of 20-30 mL has also been used in a few more studies $^{21,28}$ but is marginally superior than others (15$20 \mathrm{~mL})^{22}$ and is different from the $10 \mathrm{~mL}$ used in the interpectoral injection of the PECS II. The ideal volume for the PECS I block remains to be determined.

Our needle insertion technique diverged from Blanco's technique. We used a caudo-lateral to cranio-medial approach because of more optimal operator comfort for bilateral blocks, while still obtaining an optimal image (transverse plane view) of the pectoral branch of the thoraco-acromial artery. We need to consider the impact of different approaches (probe position and needle direction) on the efficacy of the block. For example, a cadaveric study has showed that a more lateral injection could perhaps not reach the pectoral nerves compared with a mid-clavicular approach. ${ }^{29}$ Even though our needle insertion was different from Blanco's description, we believe that it has no major impact on the end result because the needle tip lies in the same mid-clavicular area.

This study has some limitations. First, the number of volunteers studied was small. Because the PECS I block's preoperative success is rarely tested in clinical practice, it would have been interesting to have conducted this study on a larger group of volunteers to have a clearer evaluation of the PECS I block success rate. We did not find any study in the literature evaluating the success rate of this block. Second, the delay between the injection and the motor assessment was arbitrarily set at $40 \mathrm{~min}$. We chose this time delay for logistical reasons and to allow enough time to achieve maximum motor blockade. Only one other study (for the PECS II block) assessed the motor block. ${ }^{30}$ The authors did not objectively quantify motor blockade, and they used $10 \mathrm{~mL}$ of bupivacaine $0.5 \%$ with $5 \mu \mathrm{g}$ of dexmedetomidine. Onset of motor blockade was $19.2 \mathrm{~min}$. We chose to double this time to ensure a measurable motor block. Finally, it would have been interesting to test the block at different time intervals and to evaluate the total 
duration of the block. We did not assess these parameters for technical reasons.

\section{Conclusions}

A technically successful PECS I block produces a block of the pectoral nerves with accompanying motor blockade that can be objectively evaluated. Nevertheless, the PECS I block does not produce a sensory block as evaluated with dermatomal skin testing. The efficacy of the PECS I block to relieve pain remains to be proven in patients undergoing surgeries with pectoralis muscle involvement. A clinical study aiming at evaluating the efficacy of PECS I block in patients undergoing breast augmentation is underway.

Acknowledgements The authors thank Vincent Morissette-Thomas for his statistical assistance and the volunteers who participated in the study.

Conflicts of interests The authors declare no conflicts of interest.

Editorial responsibility This submission was handled by Dr. Hilary P. Grocott, Editor-in-Chief, Canadian Journal of Anesthesia.

Author contributions Jean Desroches, Marc Belliveau, Carole Bilodeau, Michel Landry, and Pierre Beaulieu were involved in the study design and planning. Jean Desroches, Marc Belliveau, Carole Bilodeau, and Michel Landry were involved in the study conduct. Jean Desroches, Marc Belliveau, Carole Bilodeau, Maxim Roy, and Pierre Beaulieu were involved in the data analysis. Jean Desroches, Marc Belliveau, Maxim Roy, and Pierre Beaulieu were involved in writing the manuscript. All authors were involved in revising the manuscript.

Funding The authors have no sources of funding to declare for this manuscript.

\section{References}

1. Blanco $R$. The, "pecs block": a novel technique for providing analgesia after breast surgery. Anaesthesia 2011; 66: 847-8.

2. Blanco $R$, Fajardo $M$, Parras Maldonado $T$. Ultrasound description of Pecs II (modified Pecs I): a novel approach to breast surgery. Rev Esp Anestesiol Reanim 2012; 59: 470-5.

3. Woodworth GE, Ivie RM, Nelson SM, Walker CM, Maniker RB. Perioperative breast analgesia: a qualitative review of anatomy and regional techniques. Reg Anesth Pain Med 2017; 42: 60931.

4. Versyck B, Van Geffen GJ, Van Houwe P. Prospective double blind randomized placebo-controlled clinical trial of the pectoral nerves (Pecs) block type II. J Clin Anesth 2017; 40: 46-50.

5. Bashandy GM, Abbas DN. Pectoral nerves I and II blocks in multimodal analgesia for breast cancer surgery: a randomized clinical trial. Reg Anesth Pain Med 2015; 40: 68-74.

6. Kulhari S, Bharti N, Bala I, Arora S, Singh G. Efficacy of pectoral nerve block versus thoracic paravertebral block for postoperative analgesia after radical mastectomy: a randomized controlled trial. Br J Anaesth 2016; 117: 382-6.

7. Wahba SS, Kamal SM. Thoracic paravertebral block versus pectoral nerve block for analgesia after breast surgery. Egypt J Anaesth 2014; 30: 129-35.

8. Goswami S, Kundra P, Bhattacharyya J. Pectoral nerve block1 versus modified pectoral nerve block2 for postoperative pain relief in patients undergoing modified radical mastectomy: a randomized clinical trial. Br J Anaesth 2017; 119: 830-5.

9. Desroches J, Grabs U, Grabs D. Selective ultrasound guided pectoral nerve targeting in breast augmentation: how to spare the brachial plexus cords? Clin Anat 2013; 26: 49-55.

10. Govshievich A, Kirkham K, Brull R, Brown MH. Novel approach to intractable pectoralis major muscle spasms following submuscular expander-implant breast reconstruction. Plast Surg Case Studies 2015; 1: 68-70.

11. Bouaziz H, Vial F, Jochum D, et al. An evaluation of the cutaneous distribution after obturator nerve block. Anesth Analg 2002; 94: 445-9.

12. Barberini F. The clavicular part of the pectoralis major: a true entity of the upper limb on anatomical, phylogenetic, ontogenetic, functional and clinical bases. Case report and review of the literature. Ital J Anat Embryol 2014; 119: 49-59.

13. Stark $T$, Walker B, Phillips JK, Fejer R, Beck R. Hand-held dynamometry correlation with the gold standard isokinetic dynamometry: a systematic review. PM R 2011; 3: 472-9.

14. Scott BW, Wallace WA, Barton MA. Diagnosis and assessment of pectoralis major rupture by dynamometry. J Bone Joint Surg Br 1992; 74: 111-3.

15. Fleury AM, Silva AC, de Castro Pochini A, Ejnisman B, Lira CA, Andrade Mdos $S$. Isokinetic muscle assessment after treatment of pectoralis major muscle rupture using surgical or non-surgical procedures. Clinics (Sao Paulo) 2011; 66: 313-20.

16. Mooers BR, Westermann RW, Wolf BR. Outcomes following suture-anchor repair of pectoralis major tears: a case series and review of the literature. Iowa Orthop J 2015; 35: 8-12.

17. Bremner-Smith AT, Unwin AJ, Williams $W W$. Sensory pathways in the spinal accessory nerve. J Bone Joint Surg Br 1999; 81: 2268.

18. Nam YS, Panchal K, Kim IB, Ji JH, Park MG, Park SR. Anatomical study of the articular branch of the lateral pectoral nerve to the shoulder joint. Knee Surg Sports Traumatol Arthrosc 2016; 24: 3820-7.

19. Akita K, Kawashima T, Shimokawa T, Sato K, Sato T. Cutaneous nerve to the subacromial region originating from the lateral pectoral nerve. Ann Anat 2002; 184: 15-9.

20. Wallaert M, Courivaud P, Mati EH, Shiniara M, Guilbert JM. Bloc interpectoral avec mise en place d'un cathéter pour analgésie postopératoire après chirurgie mammaire. Ann Fr Anesth Réanim 2014; 33: 269-71.

21. Cros J, Sengès P, Kaprelian S, et al. The pectoral block for the treatment of postoperative pain after breast cancer surgery: the pecblock prospective, randomised controlled trial. Reg Anesth Pain Med (in press).

22. Abdallah FW, MacLean D, Madjdpour C, Cil T, Bhatia A, Brull $R$. Pectoralis and serratus fascial plane blocks each provide early analgesic benefits following ambulatory breast cancer surgery: a retrospective propensity-matched cohort study. Anesth Analg 2017; 125: 294-302.

23. Sleth JC. Bloc interpectoral et chirurgie mammaire: un simple bloc intercostal par diffusion? Ann Fr Anesth Réanim 2014; 33: 548.

24. Hetta DF, Rezk KM. Pectoralis-serratus interfascial plane block vs thoracic paravertebral block for unilateral radical mastectomy with axillary evacuation. J Clin Anesth 2016; 34: 91-7. 
25. Pacik PT, Nelson CE, Werner C. Pain control in augmentation mammaplasty using indwelling catheters in 687 consecutive patients: data analysis. Aesthet Surg J 2008; 28: 631-41.

26. McCarthy CM, Pusic AL, Hidalgo DA. Efficacy of pocket irrigation with bupivacaine and ketorolac in breast augmentation: a randomized controlled trial. Ann Plast Surg 2009; 62: 15-7.

27. Layeeque $R$, Hochberg $J$, Siegel E, et al. Botulinum toxin infiltration for pain control after mastectomy and expander reconstruction. Ann Surg 2004; 240: 608-13.
28. Courivaud P, Guilbert JM, Wallaert M. Bloc interpectoral pour l'analgésie après chirurgie du sein. Prat Anesth Reanim 2013; 17: 208-10.

29. Ueshima H, Hiroshi O. Optimal site of administration of the PECS 1 block. J Clin Anesth 2017; 38: 82.

30. ELdeen HM. Ultrasound guided pectoral nerve blockade versus thoracic spinal blockade for conservative breast surgery in cancer breast: a randomized controlled trial. Egypt J Anaesth 2016; 32: 29-35. 